\title{
THE INFLUENCE OF CASTING GEOMETRY ON THE TENSILE PROPERTIES AND RESIDUAL STRESSES IN ALUMIUM CASTINGS
}

\author{
Mohsen Sadrossadat ${ }^{1, a}$, Sten Johansson ${ }^{2, b}$ \\ ${ }^{1,2}$ Division of Eng. Materials, IEI Department, Linkoping University, Sweden \\ a mohsen.sadrossadata@liu.se, ${ }^{\mathrm{b}}$ sten.jahansson@liu.se
}

Keywords: Casting modulus, microstructure, mechanical properties, geometrical stiffness, residual stresses

\begin{abstract}
The soundness and the performance of castings are significantly affected by generation and accumulation of residual stresses. This has been proven that mechanical properties and residual stresses level of the casting components are affected by thermal gradient across the casting component during cooling and some intrinsic physical properties of the material. In the present work, microstructural development, mechanical properties, residual stress evolution and cooling curves associated with different legs of a mixed-section grid castings have been investigated employing scanning electron microscope, optical microscope, 3D measurement equipment, computerized thermal data acquisition instrument and tensile testing machine. Experimental results show that the accumulated residual stress in circular, triangular and rectangular grid shapes is increasing respectively. From the results it can be seen that there are clear influences of grid's geometry on the microstructure and mechanical properties. The geometrical stiffness can affect a lot the residual stress level and the casting modulus has a big influence on the microstructure and mechanical properties.
\end{abstract}

\section{Introduction}

Aluminum silicon alloys have many benefits owing to their acceptable properties such as pressure tightness, good mechanical properties and high strength-to-weight ratio. Among a large variety of Al-Si family alloys, casting alloys has been continuously attracting the attention of materials engineering researchers and industries. B319 is one of the casting alloys which is commonly used in automotive applications. Based on Al-Si system, the main alloying elements in this alloy are copper and magnesium. To improve the mechanical properties, modification of the alloy using Al-10Sr master alloy to convert the silicon eutectic morphology from acicular to fibrous structure has been well recognized by many authors. The size of the intermetallic particles appears to be inversely proportional to the cooling rate [1-3].

Secondary dendrite arm spacing (SDAS) can be defined as the distance between the centers of two adjacent secondary arms. The improved mechanical characristics of cast structures having smaller dendrite spacings are largely due to the shorter wavelength of the periodicity of the microsegregation[4].

Density of aluminum alloys changes during solidification into two stages: solidification shrinkage in liquid state and thermal contraction in solid state. This contraction volume for aluminum alloys ranging from 4 to $7 \%$ which may result in hot tearing, dimensional changes, porosities and residual stresses [5-6]. Internal stresses in castings can be owing to the presence of temperature differences within the casting which consequently result in different amount of contraction during cooling. Since it is complicated to calculate residual stresses in pieces of complex geometry, they have to be measured [7]. Different methods for measuring residual stresses can be divided in two main groups: destructive and nondestructive. The cutting technique is an applicable method among destructive group which can be used for measuring bulk residual stresses. The basis of this method is measurement of the relaxation of strain after cutting the part [8].

Using triangular and rectangular grid castings is a well-established method for obtaining different levels of residual stresses. They consist essentially of a light outer bar designed to solidify 
rapidly and a heavier central member, the contraction of which is hindered by the relatively cold outer bar, so that tensile stresses are induced in the central member [9].

The solidification time of a casting section is given by Chvorinov's rule [10], as below:

$$
\mathrm{t}=\mathrm{C}(\mathrm{V} / \mathrm{A})^{2}=\mathrm{C}^{*} \mathrm{M}^{2}
$$

Where: $\quad \mathrm{C}=$ a constant for a given mould, alloy and casting condition

$\mathrm{A}=$ the interface area across which heat is transferred

$\mathrm{V}=$ the volume of liquid before solidification

$\mathrm{M}=$ casting modulus

This work aims at studying the effect of geometry (shape and size) of the mixed-section grid casting on residual stress level, microstructure and mechanical properties.

\section{Materials and Methods}

Experimental alloy and melting preparation. The B319.0 alloy was produced by melting and alloying in a resistance furnace. The chemical composition of the used alloy in this experiment and the standard B319.0 alloy are shown in table 1. The used alloy was prepared from commercially pure (99.85- $99.99 \% \mathrm{Wt}$ ) aluminum, magnesium, silicon and copper which were alloyed in a resistance furnace. The melt was then held at $800 \mathrm{C}$. At this temperature, the molten metal was degassed with $\mathrm{C} 2 \mathrm{Cl} 6$ tablets. Al-10Sr master alloy was then added to the melt to achieve the $\mathrm{Sr}$ level of $0.03 \%$ Wt. Finally, the molten metal poured into the oil-based sand mold cavity at $680 \mathrm{C}$.

Table1. Chemical composition of B319.0 aluminum alloy (Wt \%)

\begin{tabular}{|c|c|c|c|c|c|c|c|}
\hline & $\mathrm{Si}$ & $\mathrm{Mg}$ & $\mathrm{Mn}$ & $\mathrm{Cu}$ & $\mathrm{Fe}$ & Others & $\mathrm{Al}$ \\
\hline Standard & $5.5-6.6$ & $0.1-0.5$ & $<0.8$ & $3.5-5$ & $<0.8$ & 0.8 & Bal. \\
\hline Used alloy & 5.8 & 0.12 & 0.14 & 4 & 0.3 & 0.5 & Bal. \\
\hline
\end{tabular}

Casting design, molding set-up and thermal analysis. Practical works were followed in two steps. On the first step, three different grid shapes were cast. The main aim of this step was identifying the grid shape with lowest level of residual stress. The details of the tested grids are shown in table 2. The main result from this step showed that while circular grid shape accumulates the lowest value of residual stress, the triangular grid gives the highest level of residual stress. The second step was followed concentrating on the circular grid. A comprehensive study on the effects of changing the casting modulus of side leg on the mechanical properties and microstructure, cooling curves, and residual stresses of the grids were performed. Different dimensions used for the second step are shown in table 3. The selected thicknesses for the side leg (round bar) were from 5 to $10 \mathrm{~mm}$ while the height and the length were kept constant. Varying the wall thickness of the side leg intended to make different microstructures, mechanical properties and residual stresses in the central leg.

Due to many advantages such as smooth surfaces and dimensional accuracy, casting patterns were made by a 3D-rapid prototyping machine. For both steps, the same alloy, casting temperature, and molds were used. 
Table 2. Different shapes of the castings $(b=200 \mathrm{~mm})$

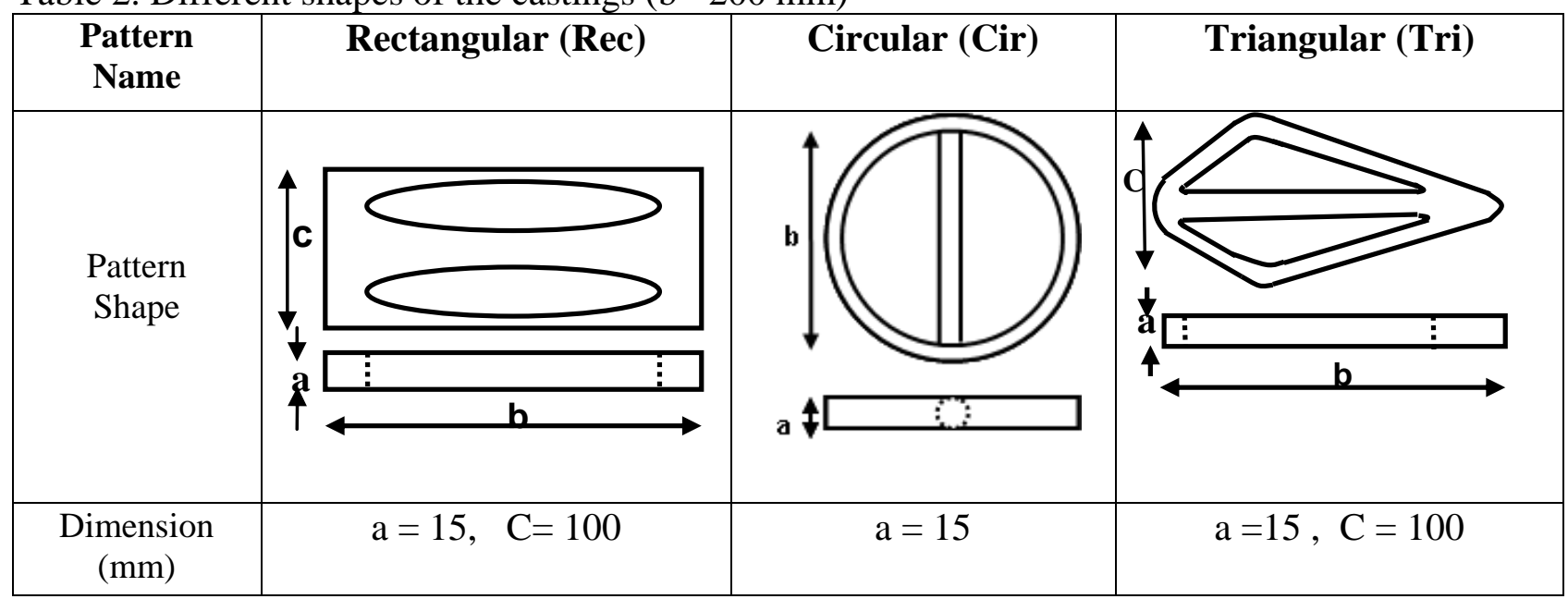

Table 3. Different dimensions of the circular shapes (mm)

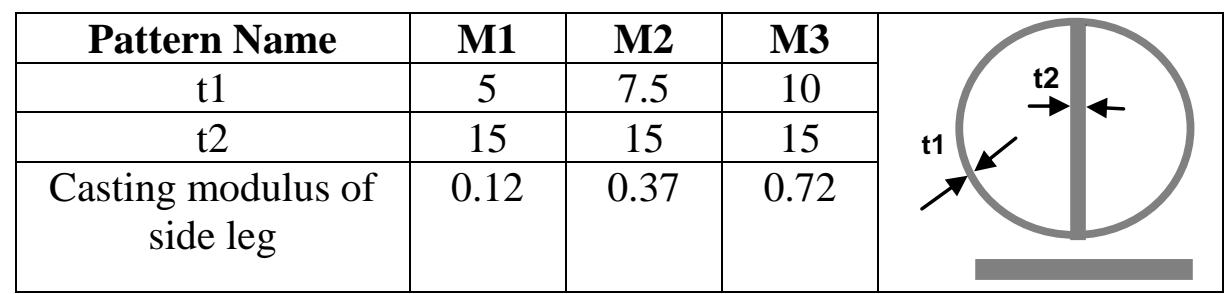

Fig. 1 shows the schematic plan view of the casting assembly in the mold which used for the second step. The sprue was perpendicular to the filter. After passing the filter the molten metal ran into the mould chamber via the gate. The purpose of using ceramic foam filter was due to necessity of lowering the turbulence of the molten metal and also to shield the casting from unwanted nonmetallic materials such as sand particles and intermetallics. An insulator behind the filter also was employed to avoid any heat transfer leakage during passing the molten metal from the filter to the central leg. From the six grids produced by casting, a cooling curve of each leg for one specimen was recorded using a programmable data logger. The locations of the $\mathrm{K}$ type thermocouples inserted in the central and side legs are illustrated in Fig. 1. Both thermal recording points were in the same direction perpendicular to the central axis of the middle leg with $25 \mathrm{~mm}$ distance from the cross point between the central and side legs.

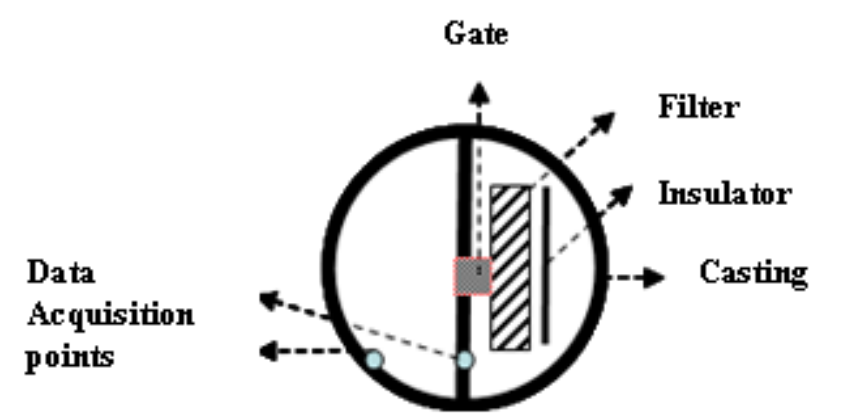

Fig. 1, The schematic plan view of cast component in the mold

Residual strain measurement. Cutting method was used to evaluate residual strain within all specimens produced by castings. As a part of this measurement two indentations were made with a certain distance on the middle bar by microhardness test equipment using $2 \mathrm{~kg}$ load than cutting the central leg of the specimens and finally measuring the distance between the mentioned indentations. Both measurement before and after cutting was done by means of $3 \mathrm{D}$ accurate measurement equipment. Due to elastic strain released by cutting the central leg, the distance between the indentations was supposed to be changed. 
Mechanical and microstructural experiments. Among six specimens of each geometry, four were selected for tensile testing and two for evaluation of the grid's stiffness by means of Instron 5580 equipment. Tensile tests were performed on the central leg of the specimens after releasing the residual stresses. Compression test along the central leg of two grids was performed. The reason for that test was to identify the stiffness of the central bar which is supposed to accumulate the tensile residual stress during cooling the side leg. Those tests were carried out according to ASTM standard methods.

All the grids were used for studying the microstructure. The SDAS values were measured in an optical microscope using a MicroGOP 2000 image analyzer software by means of intercept method and five representative readings were taken to determine the average value. The leg's samples were selected from the locations close to the thermocouples and gate specimens were taken from the bottom of sprue. The microstructural features were studied by optical and scanning electron microscopy (Hitachi SU-70) which has been equipped with an energy dispersive system (Oxford).

\section{Results and discussion}

Shape design effects. As is shown in Fig. 2, the level of the residual stress accumulated in the central leg of circular grid and triangular grid are lowest and highest respectively.

Cooling curves analysis. As shown in Fig. 3, cooling rates decrease with increasing the casting modulus of central legs; from M1 to M3. It also can be seen that while the diameter of central leg is constant for all grids, they show the same temperature decrease trend as the side legs. The reason could be related to the location of the inserted thermocouples in the middle legs which was close to the central leg. It means that the local cooling rate at the acquisition points in the central legs are somewhat affected by the rate of heat transfer from the side legs.

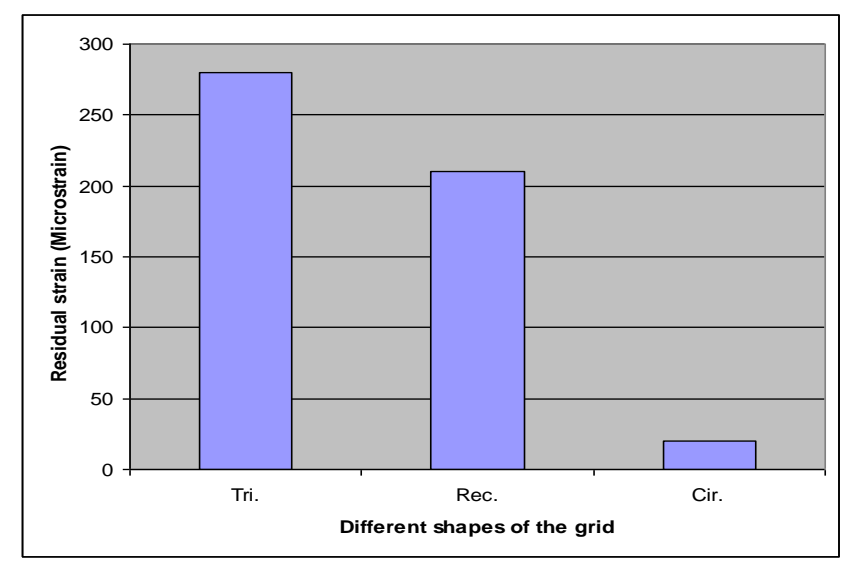

Fig. 2, Residual strain levels in different shapes

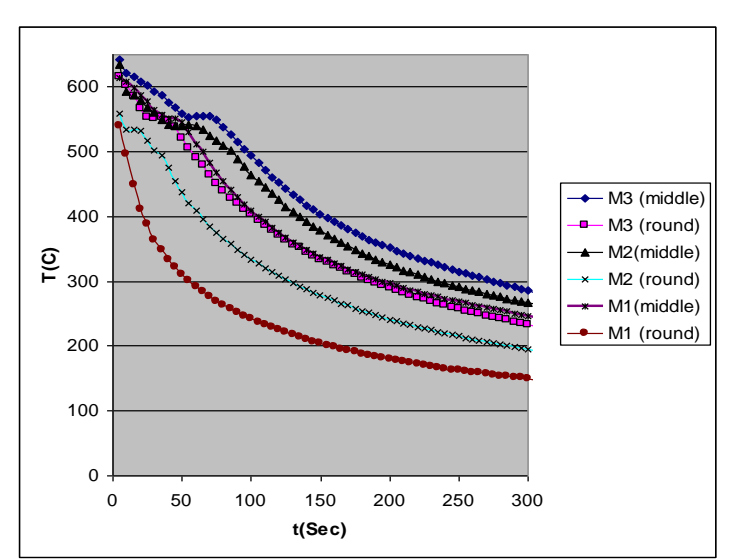

Fig. 3, Cooling curves of different legs within first 6 minutes of solidification

Fig. 4 shows that the capability of different circular grids to make the temperature difference between the legs is increasing from M3 to M1 which means that the difference increases by decreasing the casting modulus of the side leg.

Microstructural analysis. Fig. 5, shows that SDAS values of the central and side legs decrease with an increase in the casting modulus while the SDAS values for the specimens taken from the gates are constant. As it's mentioned earlier, the decreasing trend for SDAS values of central legs by increasing the casting modulus of round bar can be due to heat transfer effects of side leg on the central one. On the other hand, the stability of the SDAS values related to the gate samples can be due to the fact that they cannot be affected by the side member's heat transfer. 


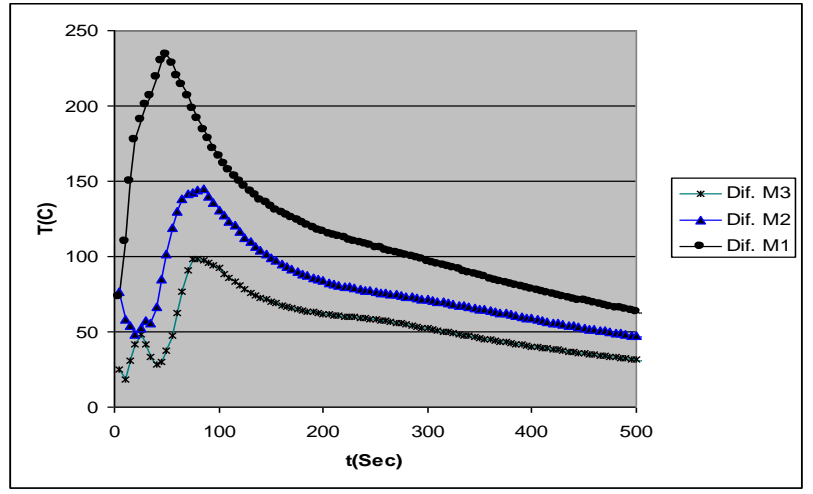

Fig. 4, Differential cooling curves for different circular grids

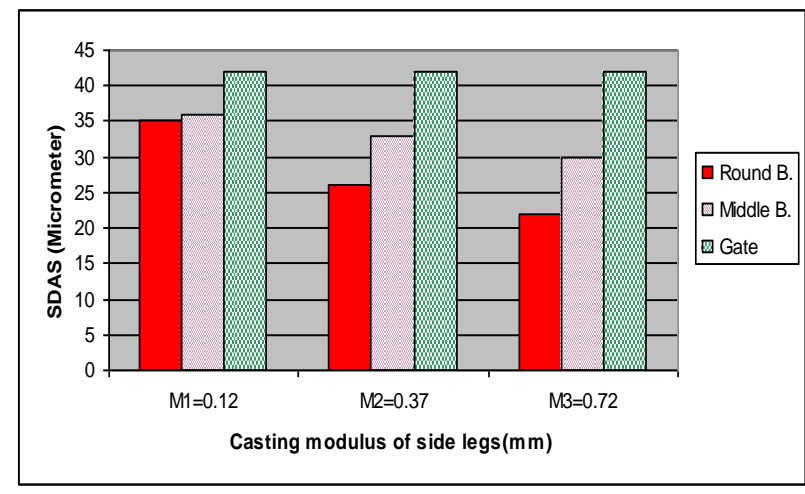

Fig. 5, SDAS values vs. casting modulus of different legs

As Fig. 6 shows, the coarseness of the microstructure increases from a $-\mathrm{c}$ which is logically correspondent to the decreasing rate of heat transfer.

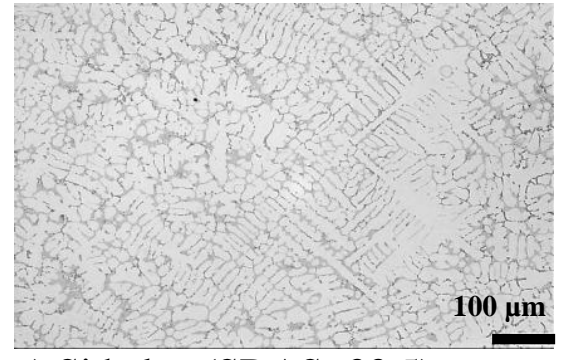

a) Side leg $(\mathrm{SDAS}=33.5)$

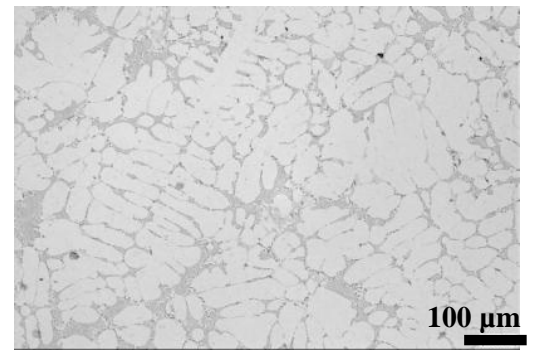

b) Central leg $(\mathrm{SDAS}=38)$

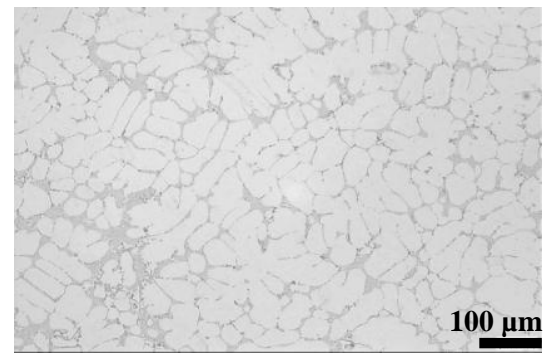

c) Gate specimen $(\mathrm{SDAS}=44)$

Fig. 6, Microstructures of different locations in M1 grid

Residual strain analysis: According to Fig. 7, there is not any tangible dependency between casting modulus of side legs and residual strains in central legs but also the level of the strains are very low, almost equal to zero.

Tensile properties analysis: As it observed in Fig. 8, there is not any meaningful relationship between the yield strength (YS), ultimate tensile strength (UTS), modulus of elasticity of the central leg (E1), modulus of elasticity of the side leg (E2) and casting modulus of the side leg for each grid. This means that cooling rate of the side leg for each grid doesn't affect the mentioned tensile properties.

On the other hand, according to the mentioned figure, there is a big difference between E1 and E2 values which should be taking into account as a very interesting fact. This indicates that changing the shape of a load carrier leg (central leg) from the straight geometry to the curved geometry can change the stiffness of the member from about $70 \mathrm{GPa}$ to almost zero. Using this dependency as a method to decrease the stiffness can be followed to lowering the residual stress level in the component. Very low level of residual stresses (see Fig. 7) can also be due to lack of stiffness of the side members. Moreover, according to the Fig. 7, there is not any considerable effect of the side leg's dimension (casting modulus) on the residual strain values. It can be concluded that the curved shape geometry has a big effect on lowering the elasticity of the frame. 


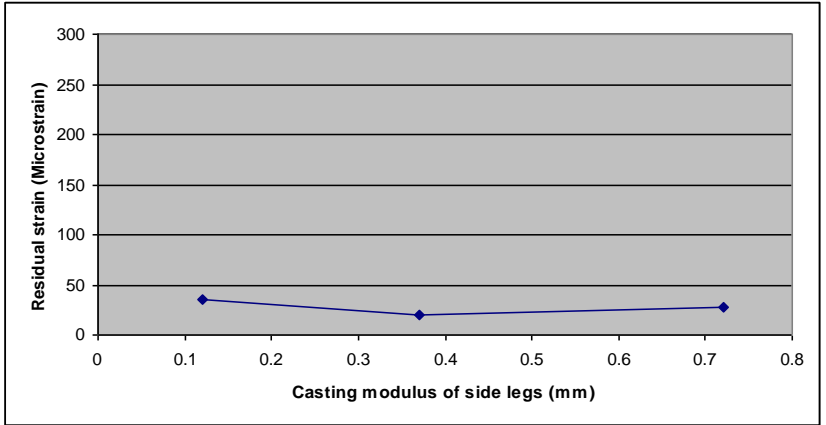

Fig.7, Casting modulus vs. Residual strain

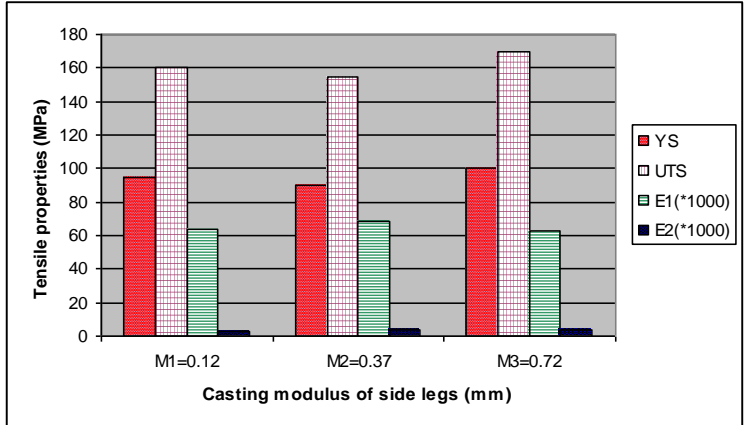

Fig. 8, Casting modulus of side legs vs. Tensile properties of the central leg

\section{Conclusion}

- Decreasing the casting modulus of the side leg of a circular grid leads to a lower temperature difference with central leg.

- While decreasing the casting modulus of the side leg, decrease SDAS values, seems not to have any effect on UTS, YS and elasticity.

- As the casting modulus increases, secondary arm spacing increases.

- Circular and rectangular designs deliver the lowest and highest level of residual stresses respectively.

- The most effective geometrical parameter on casting residual stress is geometrical stiffness with a direct effect.

- When enough elasticity is present, any increase in differential cooling rates between the legs can leads to increase of residual stresses.

- Changing the shape of the load carrying members from straight to curve can be an efficient method to decrease the residual stress level in castings.

\section{Acknowlegement}

The authors acknowledge with thanks the Stena Aluminum and Rani Metall AB Companies in Sweden for supporting us with the master alloys and casting filters, respectively.

\section{Referrences}

[1] J.E. Gruzleski: AFS Trans. Vol.100 (1992), pp. 673-683.

[2] J. Y. Hwang, H. W. Doty, M. J. Kaufman: Mater. Sci. Eng. A, Vol. A488 (2008), pp. 496-504.

[3] B. Closset and J. Gruzleski: AFS Trans. Vol 90(1982), p. 453.

[4] W.R. Osório , C.A. Santos, J.M.V. Quaresma, A. Garcia: J.of Mater. Proc.Tech. Vol 143-144 (2003), pp. 703-709

[5] I. J. Polmear: Metallury of Ligth alloys, edited by Edvard Arnold Publications, London(1981).

[6] D. G. Eskin and L.Katgerman: Mater. Sci. Forum Vol. 519-521(2006), pp.1681-1686.

[7] J. Campbell: Castings, edited by Butterworth-Heinemann Publications, London(1991).

[8] J. Withers, H.K.D.H., Bhadeshia: Residual Stress Part I- Measurement tech., Mater. Sci. Tech. Vol. 17(2001), pp. 355-365.

[9] Paper No.1037 of sub-committee T.S.32, Proceedings of the Institute of British Foundation, (1952), pp.179-189.

[10] ASM handbook: Casting, Vol. 15, Ninth edition (1998), p. 601. 